\title{
Editorial
}

\section{Saúde da criança e do adolescente: das pesquisas às políticas públicas}

Apesar dos avanços encontrados nas últimas décadas, os desafios para a equidade e integralidade na saúde de crianças e adolescentes ainda permanecem. Desafios históricos e sociais que necessitam ser vislumbrados, compreendidos e enfrentados.

A compreensão da criança e do adolescente como sujeitos de direito e de voz, então de saúde, cidadãos que precisam ser respeitados e priorizados em políticas públicas, é recente, em especial em países em desenvolvimento, como o Brasil.

0 "adulto em miniatura" e o "menor" foram termos e visões legitimadas, que ainda guardam resquícios. Neste sentido, o Estatuto da Criança e do Adolescente (ECA), promulgado em 1990, denotou avanços na garantia da proteção integral de crianças e adolescentes, legitimando-a e validando-a; mas a transposição do ECA do papel para as práticas, neste país continental, não se efetivou de forma equitativa mesmo após 30 anos de promulgação.

$\mathrm{Na}$ área da saúde, muitas iniciativas promoveram avanços no cuidado a crianças e adolescentes, tais como: Programa Nacional de Imunização; Programa Saúde na Escola; Política Nacional para Redução da Morbimortalidade por Acidentes e Violências; Política Nacional de Atenção Integral à Saúde da Criança; Diretrizes Nacionais para a Atenção Integral à Saúde de Adolescentes e Jovens na Promoção, Proteção e Recuperação da Saúde. Tais iniciativas propiciaram redução da morbimortalidade infantil e maior acesso da população adolescente a serviços de saúde e educação. Por sua vez, os inúmeros embates políticos, econômicos, sociais e jurídicos têm imposto a desconstrução destes avanços e, nos últimos anos, têm provocado retrocessos, como a equidade de gênero e educação sexual.

Esse fenômeno se faz sentir em todas as áreas da pesquisa com crianças e adolescentes, seja da área da Saúde, stricto sensu, às Ciências Humanas e Sociais. Tais aspectos têm demonstrado que a redução de investimentos em políticas de promoção da saúde e prevenção de violências redundaram no afastamento escolar, no trabalho infantil, na exploração sexual, no aumento no número de mortes violentas de adolescentes, sobretudo os negros, entre outros. Elementos estes que agravam a situação do Sistema Único de Saúde e que impactaram diretamente no desenvolvimento social e econômico do país.

Em tempos de isolamento social, devido ao COVID-19, aliado à austeridade dos "gastos" sociais, tem-se restringido o alcance das políticas públicas, recrudescendo os efeitos históricos 
da vulnerabilidade. Efeitos cujos impactos se fazem sentir e perceber, sobretudo, nas crianças e adolescentes, em sua pluralidade.

As vulnerabilidades individuais, sociais e programáticas desta população ainda se fazem evidentes. Para tanto, conceitos e estratégias como intersetorialidade, integralidade, determinantes sociais de saúde, promoção da saúde, educação permanente, prevenção da violência, acolhimento, notificação, Atenção Básica, Proteção Social Básica, território... dão a tônica desse Volume Especial, o qual pretende contribuir na busca de estratégias que promovam a saúde integral de crianças e adolescentes.

Boa leitura!

Ailton Souza Aragão

Cientista Social. Mestre em Sociologia. Doutor e Pós Doutor em Ciências da Saúde. Professor Adjunto do Departamento de Saúde Coletiva da Universidade Federal do Triângulo Mineiro. Editor Convidado.

\section{Diene Monique Carlos}

Enfermeira. Especialista em Enfermagem Pediátrica e Neonatológica. Mestre e Doutora em Enfermagem em Saúde Pública. Pós Doutora em Enfermagem Materno Infantil e Saúde Pública. Professora Adjunta do Departamento de Enfermagem da Universidade Federal de São Carlos. Editora Convidada 